\title{
Anemia and Iron Supplement in Pregnancy: A Mini Review
}

\author{
Asiyeh Namazi* \\ PhD Candidate of Health and Social Welfare, Department of social welfare, University of Social Welfare and Rehabilitation Sciences, Tehran, Iran
}

Submission: April 09, 2018; Published: April 17, 2018

*Corresponding author: Asiyeh Namazi, PhD Candidate of Health and Social Welfare, Department of social welfare, University of Social Welfare and Rehabilitation Sciences, Tehran, Iran; Email: anamazi55@yahoo.com

Abstract

Anemia during pregnancy is a public health concern throughout the world, which increases the risk of advers maternal and infant outcomes. This article investigates the benefits of routine daily iron prophylaxis and iron-folic acid supplementation on prevention of anemia during pregnancy and highlights the role of health care providers in improving awareness of nutrition intakes during pregnancy.

Keywords: Anemia Prevention, Pregnancy, Iron Supplementation

Abbreviations: WHO: World Health Organization; CDC: Center for Disease Control and Prevention; HGB: hemoglobin; UNIMAP: United Nations Multiple Micronutrient Preparation

\section{Introduction}

Iron deficiency is a major contributor to anemia that affects more than half a billion women of reproductive age [1]. Iron deficiency in pregnant women has a prevalence of $17.4 \%$ in industrialized countries, whereas in underdeveloped countries, this number is close to $60 \%$ [1]. According to the World Health Organization (WHO) criteria, pregnant women with hemoglobin (Hgb) less than $11 \mathrm{~g} / \mathrm{dL}$ or hematocrit less than 33\% [at the sea level] are considered anemic regardless of their gestational age [2]. The Center for Disease Control and Prevention (CDC) uses the same criteria to diagnose anemia as WHO, except that it has a lower threshold of $10.5 \mathrm{~g} / \mathrm{dLf}$ r hemoglobin in the second trimester [3]. There have been a number of contradictory studies on the relationship between anemia and neonatal adverse outcomes. The findings show that the low birth weight, preterm birth, maternal cardiac failure, hemorrhage, and infection are correlated with the severity of hemoglobin deficit and severity of anemia [4]. Considerable increase in plasma volume than erythrocyte volume during pregnancy results in relative anemia, which is normal and can be treated with iron supplements [5]. The increase in plasma volume slows down after mid-pregnancy [6]. Anemia test should be conducted prior to 20 weeks of gestation to avoid the difficulties in anemia detection. Bencaiova [4] recommended screening for hemoglobin and iron status in early pregnancy. Studies have shown more interstitial volume, plasma volume, and extracellular fluid volume in the intravascular space of pregnant women in their trimester than non-pregnant women
[7]. When there is a good compliance with iron supplementation and the pregnancy is uncomplicated, there is no need for hematological tests during further prenatal visits, even in cases of mild iron deficiency anemia and depleted iron stores detected in early pregnancy [4].

One of the main causes of anemia during pregnancy is iron deficiency, which has an estimated worldwide prevalence of $20 \%$ to $80 \%$ and is more common among female [8]. A study on the WHO's Vitamin and Mineral Nutrition Information System revealed that the global anemia prevalence decreased from $33 \%$ to $29 \%$ in non-pregnant women, and from $43 \%$ to $38 \%$ in pregnant women [9]. Findings of another study showed that Prevalence dropped for both sexes, particularly for male, from 1990 to 2010. Prevalence in females was higher in most regions and age groups. South Asia and Central, West, and East sub-Saharan Africa had the highest burden, while East, Southeast, and South Asia saw the greatest reductions [10]. Iron deficiency is associated with a number of adverse health consequences for both women and their children. Maternal anemia is associated with mortality and morbidity in the mother and baby, including risk of miscarriages, stillbirths, prematurity, and low birth weight [1,11-13]. On the other hand, severe maternal anemia, particularly in the first trimester, is associated with adverse outcomes, namely, preterm birth, low birth weight, intrauterine growth restriction, low Apgar score, and operative deliveries [14,15]. Iron deficiency is less common in countries that have animal proteins in their diet. 
Nonheme iron diet is not a good supplement for heme iron diet [16], since it should be changed before it can be absorbed [17]. Brown et al. [18] observed statistically significant correlation between anemia and residence, gravidity, pregnancy interval, and malaria infection during pregnancy.

\section{Prevention of Anemia}

Despite numerous research efforts, there is lack of coordinated strategies and systematic programs to effectively manage anemia throughout the world [19]. Oral iron supplements including pills, capsules, drops, and extended-release tablets are often prescribed to treat anemia. WHO recommends oral iron and folic acid supplements as part of antenatal care to reduce the risk of low birth weight, maternal anemia, and iron deficiency. In addition to iron and folic acid, supplements may be formulated to include other vitamins and minerals, according to the United Nations Multiple Micronutrient Preparation (UNIMAP), to overcome other possible maternal micronutrient deficiencies [1]. Systematic iron prophylaxis and iron-folic acid supplementation during pregnancy have been debated [20-22]. Many developed countries follow the WHO recommendations about the intermittent iron and folic acid supplementation for nonanemic pregnant women [17]. WHO and $\mathrm{CDC}$ recommend60 mg/d and $30 \mathrm{mg} / \mathrm{dIS}$ for all pregnant women, respectively. However, British guidelines do not recommend IS routinely in normal gestation.

Knowledge and practices of pregnant women based on their beliefs play an important role in anemia prevention. Namazi et al. [23] showed a statistically significant relationship between the prevalence of anemia and women knowledge. Among $86.5 \%$ of the pregnant women taking into regular iron supplements, only $20.6 \%$ knew that iron supplements should be consumed with fruit juice. Tapish [16] showed that among women in the community taking iron tablets, $61.3 \%$ found them to be beneficial, and the remaining did not feel that iron supplementation improved their health in any significant way. It was seen that of the women taking regular iron supplements, $58.1 \%$ took the tablets with food, $98.2 \%$ thought that iron tablets should be taken with milk or water, and only $29.7 \%$ thought that the tablets should be taken with orange juice toget the best results. The absorption of iron is inhibited by calcium, approximately $40 \%$, which is most abundant in milk and milk products, by polyphenols in tea, coffee, and some wines and by phytates in cereal products such as bread. Milman [24] recommends ferrous iron supplements to be taken between meals and preferably with a good source of Vitamin C such as juice to boost the iron absorption.

\section{References}

1. (2011) World Health Organization. Hemoglobin concentrations for the diagnosis of anemia and assessment of severity. Vitamin and Mineral Nutrition Information System, USA.

2. Breymann Ch (2013) Iron deficiency anemia in pregnancy. Expert Review of Obstetrics \& Gynecology 8(6): 587-596.

3. (1998) Centers for Disease Control and Prevention. Recommendations to prevent and control iron deficiency in the United States. MMWR Recomm Rep 47(RR-3): 1-29.

4. Bencaiova G, Breymann Ch (2014) Mild anemia and pregnancy outcome in a swiss collective. Journal of Pregnancy, p. 7.

5. Brown MA, Gallery ED (1994) Volume homeostasis in normal pregnancy and preeclampsia: physiology and clinical implications. Baillieres Clin Obstet Gynaecol 8: 287-310.

6. Ouzounian JG, Elkayam U (2012) Physiologic changes during normal pregnancy and delivery. Cardiol Clin 30(3): 317-329.

7. Addis Alene K, Mohamed Dohe A (2014) Prevalence of anemia and associated factors among pregnant women in an urban area of eastern Ethiopia. Anemia, p. 7.

8. (2014) WHO Global nutrition targets 2025: anemia policy brief (WHO/ NMH/NHD/14.4). World Health Organization, Geneva, USA.

9. Stevens RA, Finucane MM, De RegilL M, PaciorekCh J, Flaxman S R, et al. (2013) Global, regional, and national trends in hemoglobin concentration and prevalence of total and severe anemiain children and pregnant and non-pregnant women for1995-2011: a systematic analysis of population-representative data. Lancet Glob Health 1: e1625.

10. Kassebaum N J, Jasrasaria R, Naghavi M, Wulf S K, Johns N, et al. (2014) A systematic analysis of global anemia burden from 1990 to 2010 Blood 123(5): 615-624.

11. Ahankari A, Leonardi Bee J (2015) Maternal hemoglobin and birth weight: systematic review and meta-nalysis. International Journal of Medical Science and Public Health 4(4).

12. Radlowski EC, Johnson RW (2013) Perinatal iron deficiency and neurocognitive development. Frontiers in Human Neuroscience 7(585): 1-11.

13. Moghaddam Tabrizi F, Barjasteh S (2015) Maternal Hemoglobin Levels during Pregnancy and their Association with Birth Weight of Neonates. Iranian Journal of Pediatric Hematology Oncology 5(4): 211-217.

14. Levy A, Fraser D, Katz M, Mazor M, Sheiner E (2005) Maternal anemia during pregnancy is an independent risk factor for low birthweight and preterm delivery. European Journal of Obstetrics \& Gynecology and Reproductive Biology 122(2): 182-186.

15. Patra S, Pasrija S, Trivedi SS, Puri M (2005) Maternal and perinatal outcome in patients with severe anemia in pregnancy. International Journal of Gynecology and Obstetrics 91(2): 164-165.

16. Tabish H, Li Yu sh (2010) Awareness of Iron Deficiency Anemia among Women of Reproductive Age in Hubei Province, China. Asian Journal of Medical Sciences 1: 12-13.

17. Friedrisch JR, Friedrisch BK (2017) Prophylactic Iron Supplementation in Pregnancy: A Controversial Issue. Biochemistry Insights 10: 1-8.

18. Brown MA, Zammit VC, Mitar DM (1992) Extracellular fluid volumes in pregnancy induced hypertension. J Hypertens 10: 61-68.

19. (2016) World Health Organization. Strategies to prevent anemia: Recommendations from an expert group consultation, USA.

20. Kumar A, Jain S, Singh NP, Singh T (2005) Oral versus high dose parenteral iron supplementation in pregnancy. International Journal of Gynecology and Obstetrics 89(1): 7-13.

21. Milman N (2006) Iron prophylaxis in pregnancy general or individual and in which dose?. Annals of Hematology (12): 821-28.

22. Sanghvi G, Harvey PWJ, Wainwright E (2010) Maternal iron-folic acid supplementation programs: evidence of impact and implementation. Food and Nutrition Bulletin 31(2): S100-S107. 
23. Namazi A, Alizadeh Sh (2016) Health knowledge of pregnant women on anemia and its complication in pregnancy. J Holist Nurs Midwifery 26(2): 98-106.

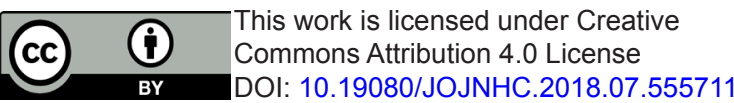

24. Nils Milman (2012) Oral Iron Prophylaxis in Pregnancy: Not Too Little and Not Too Much. Journal of Pregnancy, p. 1-8.

\section{Your next submission with Juniper Publishers will reach you the below assets}

- Quality Editorial service

- Swift Peer Review

- Reprints availability

- E-prints Service

- Manuscript Podcast for convenient understanding

- Global attainment for your research

- Manuscript accessibility in different formats

( Pdf, E-pub, Full Text, Audio)

- Unceasing customer service

Track the below URL for one-step submission https://juniperpublishers.com/online-submission.php 